DOI: http://dx.doi.org/10.18203/2320-1770.ijrcog20164356

\title{
Moving closer to an ideal tocolytic agent
}

\section{Nikita Mohan Gadam*, Swarnalata Samal}

Department of Obstetrics and Gynaecology, DMIMSU, Wardha, Maharashtra, India

Received: 10 October 2016

Accepted: 03 November 2016

*Correspondence:

Dr. Nikita Mohan Gadam,

E-mail: nikitagadam10@gmail.com

Copyright: (C) the author(s), publisher and licensee Medip Academy. This is an open-access article distributed under the terms of the Creative Commons Attribution Non-Commercial License, which permits unrestricted non-commercial use, distribution, and reproduction in any medium, provided the original work is properly cited.

\section{ABSTRACT}

Background: In the modern era of obstetrics with years of extensive research, the incidence of preterm birth remains unchanged. Tocolysis, pharmacological inhibition of premature labor is the mainstay of treatment for preterm labor. Methods: This is a prospective study. 100 antenatal cases between 28-36 weeks gestation fulfilling the inclusion criteria with preterm labor were included in the study. They were started on capsule Nifedipine for management of preterm labor. Primary outcome was to see for prolongation of pregnancy $>48$ hours. The mean prolongation of pregnancy was also assessed. Secondary outcome was to assess the maternal side effects and the neonatal outcome.

Results: Mean prolongation of pregnancy was 22.39 days. Success rate of drug treatment was $89 \%$. Maternal side effects like headache, tachycardia and facial flushing were seen. No major neonatal side effects were seen.

Conclusions: The ease of administration, the low cost, along with the good efficacy and safety, Nifedipine could be considered as one of the first choice agent for tocolysis.

Keywords: Nifedipine, Preterm labor, Tocolysis

\section{INTRODUCTION}

In the modern era of obstetrics with years of extensive research, the incidence of preterm labor still remains unchanged. Preterm labor is a huge problem for the entire family and for society as a whole because it commonly results in a premature baby.

Every year, an estimated 15 million babies worldwide are born preterm and this number is rising. An estimated 1 million babies die annually from preterm birth complications. Across 184 countries, the rate of preterm birth ranges from $5 \%$ to $18 \%$ of babies born (WHO 2012). Over $60 \%$ of preterm births occur in Africa and south Asia, but preterm birth is truly a global problem; countries with the highest numbers include Brazil, India, Nigeria and the United States of America. ${ }^{1-2}$ Preterm labour and delivery is one of the biggest challenges for obstetricians and so are the preterm babies for the paediatricians. ${ }^{3}$
Preterm birth, defined as birth before 37 weeks of gestation, is the single most important determinant of adverse infant outcomes, in terms of survival and quality of life. ${ }^{4}$ Complications of prematurity are the single largest cause of neonatal death and the second leading cause of deaths among children under the age of 5 years. Global efforts to further reduce child mortality demand urgent action to address preterm birth.

Infant death and morbidity following preterm birth can be reduced through interventions provided to the mother before or during pregnancy, and to the preterm infant after birth. However, the most beneficial set of maternal interventions are those that could improve survival chances and health outcomes of preterm infants when preterm birth is inevitable. These interventions are provided to the mother shortly before, between or during the birth process with the aim of overcoming immediate and future health challenges of the preterm infant. ${ }^{5} \mathrm{~A}$ reduction in preterm delivery can occur only through a better understanding of the physiology of labor, identification of the risk factors associated with preterm 
delivery, prediction and prevention of its occurrence and effective tocolysis.

Tocolysis (a term proposed by Mosler and Schwalm in Germany) means pharmacological inhibition of premature labor. Because uterine contractions are the most frequently recognized symptom and sign of preterm labor, inhibition of uterine contractility with tocolytic agents to prolong pregnancy and reduce neonatal complications continues to be the focus of treatment of preterm labor. Several agents with different modes of action have been used for the inhibition of uterine contractility, but it remains unclear what the first-line tocolytic agent should be.

In spite of international guidelines like RCOG which state that nifedipine or atosiban should be used as first line tocolytics, ritodrine and isoxsuprine (betamimetics) continue to be used as the most common tocolytics in India, even though nifedipine is widely available in India. ${ }^{6}$ Hence a need for this study was felt in spite of the strong evidence from several international studies.

\section{METHODS}

It is a Prospective study carried out in the Department of Obstetrics and Gynecology AVBRH, DMIMSU, Sawangi, Wardha over a period of two years from September 2014 to August 2016.

Written informed consent was taken from the subjects recruited in the study. 100 antenatal cases with painful intermittent uterine contractions are considered for the study. Women with singleton pregnancy between 28-36 weeks of gestation with regular painful uterine contractions 1-2 every 10 minutes, with cervical dilatation $<3 \mathrm{cms}$ and with intact membranes were included in the study.

Female patients with systemic diseases like diabetes mellitus, cardiac diseases, liver or renal diseases, obstetric complications like severe pregnancy induced hypertension, eclampsia, antepartum haemorrhage, polyhydramnios, hyperthyroidism, foetal complications like chorioamnionitis, IUGR, congential anomaly, foetal distress, oligohydramnios, multifoetal gestation were excluded from the study.

A detailed present and past obstetric history (history of abortions, history of previous preterm, history of any uterine anomalies) was taken.

History related to aetiology of preterm labor like history of any systemic infections (like urinary tract infection, upper respiratory tract infection, history of cervicovaginal infection), history of physical stress and history of coitus during pregnancy was assessed. Vital baseline parameters like pulse, blood pressure and temperature were recorded. Detailed per abdomen, per speculum and per vaginal examinations were done. Routine investigations were carried out.

Patients were treated with capsule Nifedipine 20mg (2 capsules) orally initially followed by capsule nifedipine 10mg 6-8 hourly (as per RCOG guidelines) adjusted according to the uterine contractions, total dose not exceeding $60 \mathrm{mg} /$ day. The treatment was discontinued in case the blood pressure is less than 90/60 $\mathrm{mm} \mathrm{Hg}$. Frequency and strength of uterine contractions, fetal heart rate, maternal pulse, blood pressure and respiratory rate, were monitored in both groups every $1 / 2$ hourly for 2 hours and then 6 hourly. Treatment was discontinued, if there was maternal tachycardia greater than 110 beats/ minute; drop of blood pressure by $15 \mathrm{~mm} \mathrm{Hg}$ or more from the baseline diastolic pressure, fever with the temperature more than $100^{\circ} \mathrm{F}$ or rupture of membranes. Patients were discharged on tablet Nifedipine $10 \mathrm{mg} 8$ hourly once the uterine contractions were subsided. Maintenance dose was continued till 37 weeks of gestation or till delivery whichever came first. These patients were followed up on weekly basis. All the patients were followed up till delivery and the maternal and neonatal outcomes were noted in both groups.

Treatment was considered successful, if there was abolition of uterine contraction, no progression of cervical dilatation, and if contractions did not recur within $48 \mathrm{hrs}$ of cessation of therapy. Treatment was deemed failure, if uterine relaxation was not achieved despite giving maximal dose of drug mentioned for both groups or any significant maternal or fetal side effects developed that necessitated discontinuation of therapy.

\section{RESULTS}

100 women with singleton pregnancies were enrolled for the study. In the present study, primiparas were more $(60 \%)$ as compared to multipara $(40 \%)$. The mean maternal age was $23.71 \pm 3.43$. In our study $88 \%$ women were booked and had regular antenatal checkups. $84 \%$ of women were from a lower socioeconomic status in our study. Majority of the patients in the present study were between 31-36 weeks of gestation (83\%). The mean gestational age at presentation was 33.15 weeks.

Table 1: Distribution of cases of according to Gestational age at admission.

\begin{tabular}{|ll|}
\hline Gestational age (in weeks) & $\begin{array}{l}\text { Nifedipine tocolysis } \\
\mathbf{N}=100(\%)\end{array}$ \\
\hline $28-30$ & $17(17 \%)$ \\
\hline $31-33$ & $41(41 \%)$ \\
\hline $34-36$ & $42(42 \%)$ \\
\hline Total & 100 \\
\hline Mean weeks & 33.15 \\
\hline Minimum weeks & 28.10 \\
\hline Maximum weeks & 36.40 \\
\hline SD & 2.07 \\
\hline
\end{tabular}


The most common complaint the women presented with was abdominal pain seen in $86 \%$ of women. White discharge per vaginum, burning micturation, loose stools, and hardening of abdomen were the other complaints the women in our study presented with. Women were also analysed for risk factors. The most common risk factor found was infection seen in $46 \%$ women. History of abortion (12\%), history of previous preterm delivery $(11 \%)$ and physical stresses $(8 \%)$ were the other risk factors seen for preterm labor.

Table 2: Total duration of prolongation of pregnancy prolongation of pregnancy.

\begin{tabular}{|ll|}
\hline $\begin{array}{l}\text { Prolongation of pregnancy } \\
\text { (days) }\end{array}$ & $\begin{array}{l}\text { Nifedipine tocolysis } \\
\mathbf{N}=100(\%)\end{array}$ \\
\hline Mean & 22.39 \\
\hline Minimum & 1 \\
\hline Maximum & 60 \\
\hline
\end{tabular}

In our study, mean prolongation of pregnancy was 22.39 days (Table 2), which depends on the gestational age at the onset of tocolytic therapy and the time from the onset of therapy to delivery. Treatment was considered successful if the pregnancy was prolonged for $>48$ hours. The success rate with the use of nifedipine in our study was $89 \%$ (Table 5). In 11 women pregnancy could not be prolonged for $>48$ hours after starting drug therapy. Period of gestation at the time of delivery was $\leq 37$ weeks in $73 \%$ of cases (Table 3 ).

Table 3: Gestational age at delivery (in days).

\begin{tabular}{|ll|}
\hline Gestational age at delivery & Nifedipine tocolysis \\
\hline$<37$ weeks & $60 \%$ \\
\hline$\geq 37$ weeks & $40 \%$ \\
\hline mean & 36.25 \\
\hline
\end{tabular}

Table 4: Maternal side effects.

\begin{tabular}{|ll|}
\hline Maternal side effects & Nifedipine tocolysis (\%) \\
\hline Headache & $12 \%$ \\
\hline Tachycardia & $12 \%$ \\
\hline Hypotension & $3 \%$ \\
\hline palpitations & $9 \%$ \\
\hline
\end{tabular}

In our study, headache was noted in 12 patients and tachycardia was noted in 12 patients. While the other side effects like facial flushing was noted in 9 patients and hypotension in 4 patients. No other serious side effects that required discontinuation of therapy was seen in our study (Table 4).

In the present study, mean birth weight of infants delivered is $2.39 \mathrm{kgs}$ with APGAR scores of $>7$ at $1^{\prime}$ and $5^{\prime}$ are $98 \%$ and $99 \%$ respectively. In the present study RDS was seen in 3 infants while foetal tachycardia was observed in 10 infants. All 3 babies who had mild RDS and were in NICU for nearly 5-6 days and were discharged with the mother.

Table 5: Result of therapy.

\begin{tabular}{|ll|}
\hline Result of therapy & Nifedipine tocolysis (\%) \\
\hline Success & $89 \%$ \\
\hline Failure & $11 \%$ \\
\hline
\end{tabular}

\section{DISCUSSION}

Determination of efficacy and safety of tocolytic agents has been a difficult task because the cause of preterm labour is generally unknown. Therefore therapy cannot be directed to a specific cause. This prospective study was designed to find out the safety, efficacy and perinatal outcome of Nifedipine in women with preterm labour.

In the present study preterm labour was more common in patients of younger age group that is between 18-25 years of age $(72 \%)$ and in primipara's $(60 \%)$.

In a study by Kawaljit Kaur et al higher incidence of preterm labor was found in primipara compared to multipara. $^{7}$

In a study by Thierry Prazuck et al on risk factors for preterm delivery in burkina faso (West Africa) identified Primiparity as one of the risk factors for preterm labor. ${ }^{8}$

There is an association of preterm labour with low socioeconomic status as seen in this study, where majority of cases belong to lower class (84\%). According to Whitehead NS et al, under circumstances of socioeconomic deprivation the mechanism of labor may be triggered prematurely through effect of chronic malnutrition, reproductive excess, life stress or infection of genital urinary tract. ${ }^{9}$ It was also confirmed by Barden were the common cases of preterm labour was of socio economic deprivation and Meis and Colleagues found that preterm labour associated with poverty, low maternal weight gain. ${ }^{10,11}$

Majority of the patients belonged to 31-36 weeks of gestation $(83 \%)$. There is increased association of preterm labour with infection $(46 \%)$, previous history of abortion (12\%) and previous history of preterm delivery $(11 \%)$ which was seen in this study.

Caroline Moreau conducted a study on previous abortions and the risk of preterm delivery. ${ }^{12}$ They concluded that a history of induced abortion increased the risk of preterm births, particularly extremely preterm deliveries. We believe both infectious and mechanical mechanisms may be involved leading to preterm labor in these women.

According to Brian M. Mercer prior spontaneous preterm delivery is highly associated with recurrence in the current gestation. ${ }^{13}$ This highlights the increased 
incidence of preterm labor in women with previous preterm delivery which is also seen in the present study.

In the present study successful tocolysis was achieved in $89 \%$ of Nifedipine and was more successful in suppressing labour for 8 days to 28 days. The success rate was comparable to Raymajhi et al $(81 \%)$ and Kedar et al $(88 \%)$ study. ${ }^{14,15}$ The mean prolongation of pregnancy was 22.39 days with Nifedipine in the present study which was comparable to Kedar et al study (22.4days). The mean gestational age at delivery was 36.25 weeks in the present study.

Tachycardia (12\%), headache (12\%) and facial flushing $(9 \%)$ were the common side effects in the present study. Headache (12\%) and facial flushing (9\%) is seen more in the nifedipine group as compared to isoxsuprine group. This is comparable to Rayamajhi et al and Kedar et al studies..$^{14,15}$

According to a study by Blumenfeld YJ et al, most frequent maternal side-effect seen with the use of Nifedipine was headache which is associated with the transient hypotension caused by the loading doses. ${ }^{16}$

In the present study, mean birth weight of infants delivered is $2.39 \mathrm{kgs}$ with APGAR scores of $>7$ at 1 ' and $5^{\prime}$ are $98 \%$ and $99 \%$ respectively. In the present study RDS was seen in 3 infants while foetal tachycardia was observed in 10 infants. All 3 babies who had mild RDS and were in NICU for nearly 5-6 days and were discharged with the mother.

\section{CONCLUSION}

Prematurity continues to be a major contributor to perinatal mortality and morbidity. The approaches which prevent and treat preterm labour will have great impact on society and long term public health care costs. Prevention of preterm labour by tocolysis has been found to be better than no tocolysis. The measure taken to prolong pregnancy has shown to reduce neonatal morbidity and mortality.

Calcium channel blockers (Nifedipine) scores in terms of maternal safety profile and the neonatal outcome. However the significance could be accountable only when a comparative study is done with other tocolytics. Considering the ease of oral administration of Nifedipine and cost effectiveness along with the evidence of better efficacy and safety of the drug, Nifedipine could be considered as one of the first choice agent for tocolysis.

\section{ACKNOWLEDGEMENTS}

We acknowledge the contribution of all patients and doctors of Department of Obstetrics and Gynecology, DMIMSU, involved in this study.
Funding: No funding sources

Conflict of interest: None declared

Ethical approval: The study was approved by the Institutional Ethics Committee

\section{REFERENCES}

1. Begum F, Buckshee K, Pande JN. Risk factors associated with preterm labor. Bangladesh Med Ras Coune Bull. 2003;29:59-66.

2. Blencowe H, Cousens S, Oestergaard M. National, regional and worldwide estimates of preterm birth. The Lancet. 2012;9; 379(9832):2162-72.

3. Singh N, Singh U, Seth S. Comparative study of Nifedipine and isoxsuprine as tocolytics for preterm labour. The journal of obstetrics and gynecology of India. 2011;61(5):512-5.

4. McCormick MC. The contribution of low birth weight to infant mortality and childhood morbidity. N Engl J Med. 1985;312(2):82-90.

5. Department of Reproductive Health and Research World Health Organization Avenue Appia 20, CH1211 Geneva 27, Switzerland.

6. RCOG. Tocolytic drugs for women in preterm labour. Clinical Guideline No. 1 (B). October 2002.

7. Kaur J, Kaur K. Obstetric complications: Primiparity Vs. Multiparity. European Journal of Experimental Biology. 2012;2(5):1462-8.

8. Prazuck T, Tall F, Roisin AJ, Konfe S, Cot M, Lafaix C. Risk Factors for Preterm Delivery in Burkina Faso (West Africa). Int J Epidemiol International Journal of Epidemiology. 1993;22(3):489-94.

9. Whitehead NS. The Relationship of Socioeconomic Status to Preterm Contractions and Preterm Delivery. Mat and Child Heal J. 2012 May;16(8):1645-56.

10. Barden TP, Peter JB, Merkatz IR. Ritodrine hydrochloride: a betamimetic agent for use in preterm labor. I. pharmacology, clinical history, administration, side effects, and safety, Obstet Gynecol. 1980;56(1):1-6.

11. Meis PJ, Michielutte R, Peters TJ, Wells HB, Sands $\mathrm{RE}$, Coles EC, et al. Factors associated with preterm birth in Cardiff, Wales. II. Indicated and spontaneous preterm birth, Am J Obstet Gynecol. 1995;173:597602.

12. Mercer BM, Goldenberg RL, Moawad AH, Meis PJ, Iams JD, Das AF, et al. The Preterm Prediction Study: Effect of gestational age and cause of preterm birth on subsequent obstetric outcome. American Journal of Obstetrics and Gynecology. 1999;181(5):1216-21.

13. Moreau C, Kaminski M, Ancel P, Bouyer J, Escande B, Thiriez G. Previous induced abortions and the risk of very preterm delivery: Results of the EPIPAGE study. BJOG: An International Journal of Obstetrics and Gynaecology. 2005;112(4):430-7.

14. Rayamajhi R, Pratap K. A comparative study between Nifedipine and Isoxsuprine in the 
suppression of preterm labour. Kathamandu University Medical J. 2003;1(2):85-90.

15. Ganla KM, Shroff SA, Desail S. A prospective comparison of Nifedipine and Isoxsuprine for tocolysis. Bombay Hospital J. 1999;259.
16. Blumenfeld YJ, Lyell DJ. Prematurity prevention: the role of acute tocolysis. Current Opinion in Obstetrics and Gynecology. 2009;21(2):136-41.

Cite this article as: Gadam NM, Samal S. Moving closer to an ideal tocolytic agent. Int J Reprod Contracept Obstet Gynecol 2016;5:4419-23. 